CLINICAL STUDY

\title{
GNRH analog therapy in girls with early puberty is associated with the achievement of predicted final height but also with increased risk of polycystic ovary syndrome
}

\author{
Valentina Chiavaroli ${ }^{1}$, Marco Liberati $^{2}$, Francesco D'Antonio ${ }^{2}$, Fabio Masuccio ${ }^{1}$, Rita Capanna ${ }^{1}$, Alberto Verrotti $^{1}$, \\ Francesco Chiarelli ${ }^{1}$ and Angelika Mohn ${ }^{1}$ \\ Departments of ${ }^{1}$ Pediatrics and ${ }^{2}$ Obstetrics and Gynecology, University of Chieti, Via dei Vestini 5, 66100 Chieti, Italy \\ (Correspondence should be addressed to A Mohn; Email: amohn@unich.it)
}

\begin{abstract}
Objective: GNRH analog (GNRHa) therapy has not been supported by beneficial effects on adult stature in girls with early puberty. Furthermore, an increased prevalence of polycystic ovary syndrome (PCOS) has been described in girls treated for central precocious puberty. Women with PCOS are at increased risk of cardiometabolic dysfunctions and infertility. Our aim was to assess GNRHa effectiveness on reaching adult stature and the risk of PCOS in girls with early puberty.

Design: Longitudinal study of GNRHa-treated and GNRHa-untreated girls at baseline and at final height.

Methods: Twenty-five GNRHa-treated girls and 55 controls were compared. Insulin resistance (IR; homeostasis model assessment of IR (HOMA-IR) and glucose-to-insulin ratio (G/I)), the effect of GNRHa on final height, and the prevalence of PCOS were assessed.

Results: In GNRHa-treated girls, no significant difference was found between predicted final height and final height, whereas a significant difference was detected in untreated girls $(P=0.0001)$. At final height, GNRHa-treated girls showed higher HOMA-IR and lower G/I ( $P=0.03$ for both) as well as higher DHEAS and androstenedione levels $(P=0.02$ and $P=0.01$ respectively) than untreated girls. The prevalence of PCOS and hyperandrogenemia was significantly higher in GNRHa-treated adolescents than in untreated adolescents (36 and 14.5\% respectively, $P=0.04 ; 56$ and 23.6\% respectively, $P=0.01)$. Finally, gonadotropin-suppressive therapy was significantly related to PCOS during adolescence $(P=0.03)$.

Conclusions: In girls with early puberty, GNRHa therapy is associated with the achievement of predicted final height; nevertheless, this treatment seems to act as an independent risk factor for the development of PCOS already during adolescence.
\end{abstract}

European Journal of Endocrinology 163 55-62

\section{Introduction}

Early puberty, defined as the onset of secondary sex characteristics between 8 and 10 years for Caucasian girls, is associated with a compromised final height, especially in girls born from short parents (1). Furthermore, the strong association between early pubertal timing and psychosocial distress has been widely discussed (2). It has been well demonstrated that suppressive therapy with GNRH analog (GNRHa) improves final height in girls with central precocious puberty (CPP) (3). In contrast, a large body of evidence has shown that GNRHa therapy does not provide similar beneficial effects in girls with early puberty $(1,4)$. Furthermore, a high risk of developing polycystic ovary syndrome (PCOS) has been postulated in girls with CPP (5-9). PCOS is a heterogeneous endocrinopathy characterized by abnormal gonadotropin release and dysregulation of steroidogenesis (10), and based on the presence or absence of four key features: menstrual dysfunction, clinical and/or biochemical signs of androgen excess, and polycystic ovaries (11). This syndrome occurs in $4-12 \%$ of reproductive age women and often becomes symptomatic during adolescence $(12,13)$. Since it has been suggested that women with PCOS are at increased risk of developing obesity, cardiometabolic dysfunctions $(14,15)$, infertility, and endometrial carcinoma (16), a precocious diagnosis of this disorder is of utmost importance. As a matter of fact, an increased prevalence of polycystic ovaries has been described in some studies of CPP girls who received GNRHa treatment $(8,17-19)$, suggesting that gonadotropin-suppressive therapy could be critical for its development likely due to an excessive secretion of 
androgens. Despite the well-described risk of developing polycystic ovaries in CPP girls, no data is available in terms of PCOS prevalence in girls with early puberty treated with GNRHa.

The aims of this longitudinal study were to evaluate the effectiveness of GNRHa treatment on predicted final height in girls with early puberty compared with untreated subjects. Furthermore, the association between GNRHa therapy and the risk of PCOS during adolescence was investigated.

\section{Materials and methods}

Eighty Caucasian girls were recruited from the outpatient Endocrine Clinic of the Department of Pediatrics, University of Chieti, Italy, between June 1998 and December 2002, where they had been admitted for early puberty. All girls showed the following manifestations of early puberty: breast stage 2 or 3 (based on Tanner criteria) (20) with or without sexual hair for not longer than 6 months, pubertal uterine and ovarian development at pelvic ultrasonography (21), peak LH response $>5 \mathrm{UI} / \mathrm{l}$ after exogenous GNRH therapy, recent increase in growth velocity, and bone age (BA) $>1$ year above the chronological age with a predicted final height less than genetic target height.

All subjects were in good health, and none was taking any medication or presented congenital anomalies, psychomotor delay, organic brain disorders, and autoimmune diseases. Exclusion criteria included precocious puberty, defined as the onset of secondary sex characteristics before 8 years, disorders of androgen excess, congenital adrenal hyperplasia or other endocrinopathies, and being born prematurely or small for gestational age.

In accordance with our departmental policy, GNRHa therapy was discussed with all participants' families, especially with respect to the risk of not attaining genetic target height. The majority of the patients refused GNRHa therapy for several reasons, although they decided to remain under observation. Based on the acceptance or refusal, of GNRHa therapy the study population was categorized into two groups: GNRHa treated and GNRHa untreated.

\section{GNRHa-treated group}

Twenty-five girls were treated with depot triptorelin (Decapeptyl, IPSEN, Milan, Italy) at a dose of $80 \mu \mathrm{g} / \mathrm{kg}$ i.m. every 28 days. All girls took part in follow-up visits every 6 months including clinical examination and endocrine evaluation, consisting of the measurement of basal plasma gonadotropin and sex steroid levels. GNRHa therapy was discontinued when normal puberty could be expected, at $\mathrm{BA} \geq 11$ years, and/or growth velocity $<4 \mathrm{~cm} /$ years.

\section{GNRHa-untreated group}

Fifty-five girls did not accept GNRHa therapy, and were recruited as controls.

Subsequently, both groups took part in follow-up visits every 6 months until menarche. All girls were recalled for the final visit 2 or more years after menarche.

\section{Follow-up visits}

In both groups, follow-up visits were conducted at 6-month intervals by the same team until menarche. During this period, complete physical examinations including anthropometric measurements (height, height SDS, weight, body mass index (BMI), BMI SDS, and growth velocity) were done, and basal blood pressure was measured. Bone maturation rate and predicted final height were assessed yearly. Furthermore, for both groups, pelvic ultrasonography was performed yearly.

\section{Last visit at final height}

All girls were recalled for the final visit 2 or more years after menarche, when final height was achieved (BA $>15$ years). At this visit, complete physical examination was done, and basal blood pressure was measured. Staging of puberty was determined, and bone maturation rate was assessed. Pelvic ultrasonography was performed to evaluate uterine length, ovarian volume, and follicle diameter. Furthermore, in the early follicular phase of the menstrual cycle (days 2-8), fasting blood samples were obtained to evaluate basal FSH and LH, sex steroid, DHEAS and androstenedione levels, fasting insulin and glucose, insulin resistance (IR) indexes, and lipid profile.

The study was approved by the ethics committee of the University of Chieti. Written informed consent was obtained from all the parents, and oral consent was obtained from all the girls.

\section{Anthropometric measurements}

Body weight was determined to the nearest $0.1 \mathrm{~kg}$, and height was measured with the Harpenden stadiometer to the nearest $0.1 \mathrm{~cm}$. As indexes of adiposity, we used BMI (the weight in kilograms divided by the square of the height in meters) and the BMI SDS for age and gender (calculated using the formula: SDS = (individual's measurement-population mean)/population S.D.) (22).

Target heights $(\mathrm{cm})$ were calculated using Tanner's formula: ((the sum of both parents' heights - 13)/2) (23).

Bone maturation rate, determined using the Greulich \& Pyle method (24), and predicted final height, calculated using the tables of Bayley \& Pinneau (25), were assessed by a single auxologist. 


\section{Laboratory procedures}

Biochemical analysis Plasma glucose level was determined using the glucose oxidase method, and plasma insulin was measured with two-site immunoenzymometric assay (AIA-PACK IRI; Tosoh, Tokyo, Japan). The limit of detection was $0.5 \mu \mathrm{U} / \mathrm{ml}$ with intra- and interassay coefficients of variation $(\mathrm{CV})<7 \%$ for quality control.

We used the following indexes for the determination of IR: homeostasis model assessment of IR (HOMA-IR) calculated with the formula: (fasting insulin $(\mu \mathrm{U} / \mathrm{ml})$ $\times$ fasting glucose $(\mathrm{mmol} / \mathrm{l}) / 22.5)$, and fasting glucoseto-insulin ratio $(\mathrm{G} / \mathrm{I})(\mathrm{IR}$ was defined as $\mathrm{G} / \mathrm{I}<6)$.

Lipid analysis Serum total cholesterol, high-density lipoprotein (HDL), and triglyceride (TG) concentrations were determined by calorimetric enzymatic method. Low-density lipoprotein (LDL) was calculated according to the Friedewald formula: $(\mathrm{LDL}=$ total cholesterol HDL - (TG/5)).

FSH and LH analysis FSH and LH were measured with a two-site immunoenzymometric assay (ST AIA-PACK; Tosoh). The within-run $\mathrm{CV}$ for $\mathrm{FSH}$ were $2.6 \%$ at $4.96 \mathrm{mIU} / \mathrm{ml}$ and $1.5 \%$ at $60.15 \mathrm{mIU} / \mathrm{ml}$; for $\mathrm{LH}$, the within-run $\mathrm{CV}$ were $2.5 \%$ at $4.94 \mathrm{mIU} / \mathrm{ml}$ and $1.8 \%$ at $98.14 \mathrm{mIU} / \mathrm{ml}$.

Estradiol and progesterone analysis Estradiol and progesterone were determined with a competitive enzyme immunoassay (ST AIA-PACK; Tosoh). The within-run CV for estradiol were $6.1 \%$ at $110.2 \mathrm{pg} / \mathrm{ml}$ and $2.6 \%$ at $747.3 \mathrm{pg} / \mathrm{ml}$; for progesterone, the within-run CV were $9.9 \%$ at $2.07 \mathrm{ng} / \mathrm{ml}$ and $4.8 \%$ at $25.02 \mathrm{ng} / \mathrm{ml}$.

DHEAS analysis DHEAS was determined with a chemiluminescent immunoassay technology (Diasorin LIAISON). The within-run CV were $4.8 \%$ at $42.3 \mathrm{ng} / \mathrm{ml}$ and $3.5 \%$ at $169.3 \mu \mathrm{g} / \mathrm{dl}$.

Androstenedione analysis Androstenedione was determined with a RIA (AIA-PACK; Tosoh). The within-run $\mathrm{CV}$ were $5.6 \%$ at $0.71 \mathrm{ng} / \mathrm{ml}$ and $2.8 \%$ at $7.22 \mathrm{ng} / \mathrm{ml}$.

Total and free testosterone analysis Total and free testosterone were determined with a competitive enzyme immunoassay (AIA-PACK; Tosoh). The within-run $\mathrm{CV}$ for total testosterone were $8.06 \%$ at $1.13 \mathrm{ng} / \mathrm{ml}$ and $7.08 \%$ at $9.3 \mathrm{ng} / \mathrm{ml}$; for free testosterone, the within-run $\mathrm{CV}$ were $11.4 \%$ at $0.73 \mathrm{pg} / \mathrm{ml}$ and $9.3 \%$ at $33.94 \mathrm{pg} / \mathrm{ml}$.

\section{Instrumental procedures}

Blood pressure measurement Systolic blood pressure (SBP) and diastolic blood pressure (DBP) were measured twice in the right arm after 10-min rest in supine position using a calibrated sphygmomanometer, and were averaged.

Ultrasound examination Pelvic transabdominal ultrasonography scanning was performed in all the girls by a single trained and experienced operator in order to reduce the interoperator variability, using a scanner (Aloka Alpha 10 Prosound Premier) with a $5-\mathrm{MHz}$ transducer. The operator was unaware of the history and clinical course of the patients. All girls had a full bladder, which was obtained by voluntary urine retention following oral administration of fluids.

Diagnosis of PCOS PCOS was diagnosed based on the Androgen Excess Society (AES) 2006 (11) and Rotterdam 2003 criteria (26); both the criteria require the exclusion of disorders of androgen excess.

AES 2006 criteria. These criteria require the presence of the following two features: i) hyperandrogenism and/or hyperandrogenemia and ii) oligomenorrhea and/or polycystic ovaries.

Rotterdam 2003 criteria. These criteria require the presence of at least two of the following three features: i) hyperandrogenism and/or hyperandrogenemia, ii) oligomenorrhea, and iii) polycystic ovaries.

Clinical hyperandrogenism was diagnosed by the presence of hirsutism, and the modified FerrimanGallwey (mFG) score was used to detect hirsutism, with values $>8$ being considered abnormal $(27,28)$. Hyperandrogenemia was determined measuring DHEAS, androstenedione, and total and free testosterone levels. All adolescents with diagnosis of hyperandrogenemia showed at least two androgen values above the normal range. Specifically, the upper normal limits were $245.9 \mu \mathrm{g} / \mathrm{dl}$ for DHEAS, $2.496 \mathrm{ng} / \mathrm{ml}$ for androstenedione, $0.847 \mathrm{ng} / \mathrm{ml}$ for total testosterone, and $7.5 \mathrm{pg} / \mathrm{ml}$ for free testosterone $(12,29)$. Furthermore, in order to detect menstrual dysfunctions, a detailed recording of patterns was obtained from all the subjects $(11,30)$, and oligomenorrhea was defined as menstrual cycle length $>35$ days for at least three consecutive months. Polycystic ovaries were diagnosed by pelvic ultrasonography when an ovarian volume $>10 \mathrm{ml}$ was detected at least in one ovary, or when a diameter from 2 to $10 \mathrm{ml}$ was measured in at least 12 follicles $(26,31)$. Uterine and ovarian volumes were calculated according to the ellipsoid formula: (depth $\times$ length $\times$ width in $\mathrm{cm} \times 0.5233)(32)$.

\section{Statistical analysis}

All values are expressed as the means and s.D., unless otherwise stated. Statistical significance level was $P<0.05$. According to GNRHa treatment, the girls were divided into two groups: GNRHa-treated and GNRHauntreated. Given the nonnormal distribution of the variables, differences between the two groups were 
assessed by the Mann-Whitney U-test. Dichotomic variables were analyzed by $\chi^{2}$ test. Wilcoxon rank test was performed for evaluating the differences over time within GNRHa-treated girls and within GNRHauntreated girls. The odd ratio for the risk for developing PCOS was calculated with logistic regression analysis. In this model, the presence of PCOS was used as the dependent variable, and GNRHa therapy, birth weight (BW), and age together with BMI SDS and HOMA-IR at final height were used as the independent variables. Results are presented as $\operatorname{Exp}(\mathrm{B})$ (95\% confidence interval).

All calculations were made using the computer program SPSS, version 16.0 software for Windows (SPSS Inc., Chicago, IL, USA).

\section{Results}

\section{Baseline characteristics}

Baseline clinical characteristics and laboratory investigations of the study population are reported in Table 1.
The two groups were similar for chronological age, height, height SDS, weight, BMI and BMI SDS, target zone, and BA. Predicted final height was significantly higher in GNRHa-untreated girls than in GNRHatreated girls $(P=0.002)$. No significant difference between the two groups was found for SBP and DBP, lipid profile, fasting glucose and insulin, and IR indexes, as well as in terms of basal gonadotropin, sex steroid, DHEAS, and androstenedione levels.

Pelvic ultrasonography did not detect significant differences in terms of uterine size and ovarian volume between the two groups, and no patient showed clinical features of hyperandrogenism.

GNRHa-treated group underwent gonadotropinsuppressive treatment for a mean period of $1.9 \pm 0.5$ years. During the suppressive treatment, no change was found in terms of breast stage, and no girl had menarche, vaginal spotting, or side effects. The time of discontinuation was individualized based on chronological age, BA, growth velocity, and parent/patient preference. In detail, GNRHa therapy was discontinued

Table 1 Clinical characteristics and biochemical parameters of the study population at baseline and at final height. Values are means ( \pm S.D).

\begin{tabular}{|c|c|c|c|c|c|c|}
\hline & \multicolumn{3}{|c|}{ At baseline } & \multicolumn{3}{|c|}{ At final height } \\
\hline & $\begin{array}{l}\text { GNRHa-treated } \\
\text { girls }\end{array}$ & Controls & $P$ & $\begin{array}{l}\text { GNRHa-treated } \\
\text { girls }\end{array}$ & Controls & $P$ \\
\hline \multicolumn{7}{|l|}{ Clinical characteristics } \\
\hline Age (years) & $8.9 \pm 0.2$ & $9 \pm 0.2$ & NS & $14.7 \pm 0.6$ & $14.9 \pm 0.7$ & NS \\
\hline $\mathrm{BW}(\mathrm{kg})$ & $3.2 \pm 0.3$ & $3.3 \pm 0.4$ & NS & & & \\
\hline Height (cm) & $136.3 \pm 3.8$ & $138.1 \pm 3.8$ & NS & $157.4 \pm 5.2$ & $157.2 \pm 4.8$ & NS \\
\hline Height SDS & $0.9 \pm 0.9$ & $1 \pm 0.7$ & NS & $-0.4 \pm 0.8$ & $-0.4 \pm 0.8$ & NS \\
\hline Weight (kg) & $38.5+5$ & $39.6+5.8$ & NS & $58.3+4.7$ & $55.8+8$ & NS \\
\hline BMI $\left(\mathrm{kg} / \mathrm{m}^{2}\right)$ & $20.7 \pm 2.1$ & $20.7 \pm 2.8$ & NS & $23.7 \pm 2$ & $22.8 \pm 2.8$ & NS \\
\hline BMI SDS & $3.1+1.3$ & $3+1.8$ & NS & $1.5+0.7$ & $1.1+1.1$ & NS \\
\hline Target height $(\mathrm{cm})$ & $160.2 \pm 4$ & $161.7 \pm 3.6$ & NS & & & \\
\hline Predicted FH (cm) & $157.4 \pm 3.6$ & $160.1 \pm 3.8$ & 0.002 & & & \\
\hline BA (years) & $11 \pm 0.6$ & $11.1 \pm 0.5$ & NS & $15.8 \pm 0.3$ & $16 \pm 0.5$ & NS \\
\hline Age at thelarche (years) & $8.7 \pm 0.2$ & $8.8 \pm 0.1$ & NS & & & \\
\hline Age at menarche (years) & & & & $12.1 \pm 0.7$ & $10.9 \pm 0.3$ & 0.0001 \\
\hline $\mathrm{SBP}(\mathrm{mmHg})$ & $110.6 \pm 6.4$ & $110.8 \pm 6.2$ & NS & $111 \pm 7.6$ & $111.6 \pm 9.3$ & NS \\
\hline $\mathrm{DBP}(\mathrm{mmHg})$ & $65 \pm 5$ & $68.2 \pm 7.4$ & NS & $71.6 \pm 6.8$ & $71.4 \pm 8.5$ & NS \\
\hline \multicolumn{7}{|l|}{ Biochemical parameters } \\
\hline Fasting glucose $(\mathrm{mg} / \mathrm{dl})$ & $76.8 \pm 5.3$ & $79 \pm 5.3$ & NS & $85.4 \pm 4.1$ & $83.2 \pm 5.5$ & NS \\
\hline Fasting insulin $(\mu \mathrm{U} / \mathrm{ml})$ & $14.8 \pm 1.8$ & $14.4 \pm 2.2$ & NS & $27.1 \pm 5.5$ & $26.2 \pm 9.5$ & NS \\
\hline HOMA-IR & $2.8 \pm 0.4$ & $2.8 \pm 0.6$ & NS & $5.4 \pm 1.3$ & $4.7 \pm 1.5$ & 0.03 \\
\hline $\mathrm{G} / \mathrm{I}$ & $5.3 \pm 0.6$ & $5.5 \pm 0.7$ & NS & $3.2 \pm 1.3$ & $3.5 \pm 0.9$ & 0.03 \\
\hline Total cholesterol (mg/dl) & $146.8 \pm 11.7$ & $153.3 \pm 19$ & NS & $153 \pm 10.9$ & $149.2 \pm 13.7$ & NS \\
\hline $\mathrm{LDL}(\mathrm{mg} / \mathrm{dl})$ & $79.2 \pm 13.2$ & $82.6 \pm 19.5$ & NS & $79.8 \pm 13.4$ & $79.2 \pm 13.8$ & NS \\
\hline $\mathrm{HDL}(\mathrm{mg} / \mathrm{dl})$ & $53.6 \pm 2.4$ & $55.6 \pm 5.2$ & NS & $60.1 \pm 5.3$ & $56.9 \pm 7.1$ & NS \\
\hline $\mathrm{TG}(\mathrm{mg} / \mathrm{dl})$ & $69.9 \pm 20.3$ & $75.8 \pm 15.9$ & NS & $66.4 \pm 6.4$ & $71.2 \pm 12.7$ & NS \\
\hline DHEAS $(\mu \mathrm{g} / \mathrm{dl})$ & $248.1 \pm 49.6$ & $239.8 \pm 60.8$ & NS & $318.5 \pm 95.3$ & $253.3 \pm 48.3$ & 0.02 \\
\hline Androstenedione (ng/ml) & $1 \pm 0.2$ & $1 \pm 0.2$ & NS & $2.2 \pm 0.5$ & $1.9 \pm 0.5$ & 0.01 \\
\hline Total testosterone $(\mathrm{ng} / \mathrm{ml})$ & $0.2+0.1$ & $0.2+0.1$ & NS & $0.6+0.2$ & $0.5+0.1$ & NS \\
\hline Free testosterone $(\mathrm{pg} / \mathrm{ml})$ & $1 \pm 0.2$ & $0.8 \pm 0.1$ & NS & $2.5 \pm 0.2$ & $2.4 \pm 0.3$ & NS \\
\hline $\mathrm{FSH}(\mathrm{mlU} / \mathrm{ml})$ & $4.4 \pm 2.2$ & $3.7 \pm 1.7$ & NS & $4.4 \pm 1.9$ & $5.1 \pm 1.5$ & NS \\
\hline $\mathrm{LH}(\mathrm{mlU} / \mathrm{ml})$ & $4.3 \pm 1.9$ & $3.8 \pm 1.5$ & NS & $5.7 \pm 2.7$ & $5.3 \pm 1.5$ & NS \\
\hline $\mathrm{LH}$ peak $(\mathrm{mlU} / \mathrm{ml})$ & $17.9+8.7$ & $16+7.3$ & NS & & & \\
\hline Estradiol (mU/ml) & $57.5+20.6$ & $49.6 \pm 17.6$ & NS & $65.3 \pm 26.8$ & $78.6 \pm 25.5$ & NS \\
\hline Progesterone $(\mathrm{ng} / \mathrm{ml})$ & $0.2 \pm 0.1$ & $0.2 \pm 0.1$ & NS & $1.6 \pm 1.1$ & $1.1 \pm 0.3$ & NS \\
\hline
\end{tabular}

NS, no significant difference $(P>0.05)$. GNRHa, GNRH analog; BW, birth weight; BMI, body mass index; FH, final height; BA, bone age; SBP, systolic blood pressure; DBP, diastolic blood pressure; HOMA-IR, homeostatic model assessment of insulin resistance; G/I, fasting glucose (G)/fasting insulin (I); LDL, low-density lipoprotein; HDL, high-density lipoprotein; TG, triglyceride. 
at a mean age of $11.1 \pm 0.5$ years, with a mean BA of $12.3 \pm 0.6$ years and a predicted final height of $158 \pm 4.2 \mathrm{~cm}$.

At discontinuation of the suppressive treatment, treated girls showed higher BMI and BMI SDS than untreated girls $(P=0.0003$ and $P=0.0004$ respectively). One year later, no significant difference was found in terms of BMI and BMI SDS between the two groups.

As expected, the mean age of menarche was significantly different between the two groups $(P=0.0001)$.

\section{Final height characteristics}

Clinical characteristics and laboratory investigations of the study population detected at final height are reported in Table 1. No significant difference was detected in terms of chronological age, height, height SDS, weight, BMI, and BMI SDS between the two groups. All patients had pubertal characteristics corresponding to stage 5 , and were similar for BA. No significant difference was found between the two groups for SBP and DBP, lipid profile, and fasting glucose and insulin; in contrast, HOMA-IR and G/I were respectively higher and lower in the GNRHa-treated group than in the controls ( $P=0.03$ for both).

Furthermore, significantly higher DHEAS and androstenedione levels were detected in GNRHa-treated girls than in the untreated group $(P=0.02$ and $P=0.01$ respectively). Moreover, the mean value of total and free testosterone levels was higher in GNRHa-treated girls than in untreated girls, although these differences did not reach statistical significance. No significant differences were detected in terms of FSH, LH, estradiol, and progesterone levels.

\section{Intragroup differences between baseline and final height}

In GNRHa-treated girls, there was no significant difference between predicted final height and achieved final height $(157.4 \pm 3.6$ and $157.4 \pm 5.2 \mathrm{~cm}$ respectively; $P=0.8$ ); in contrast, a significant difference was detected between predicted final height and achieved final height in the untreated group $(160.1 \pm 3.8$ and $157.2 \pm 4.8 \mathrm{~cm}$ respectively; $P=0.0001$ ).

\section{Prevalence of PCOS and its diagnostic criteria}

Using the AES 2006 criteria, out of the 80 adolescents, the prevalence of PCOS was significantly higher in GNRHa-treated adolescents than in untreated adolescents ( 36 and $14.5 \%$ respectively; $P=0.04$ ); also using the Rotterdam 2003 criteria, the prevalence of PCOS was significantly higher in GNRHa-treated adolescents

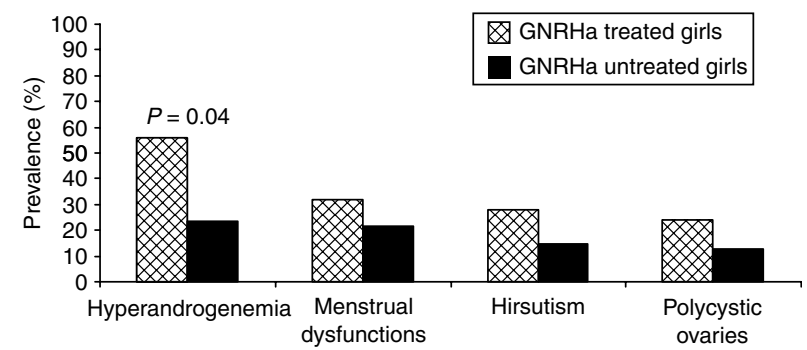

Figure 1 Prevalence of PCOS components in GNRHa-treated and GNRHa-untreated girls at final height.

than in untreated adolescents (40 and $16.4 \%$ respectively; $P=0.04$ ). Specifically, GNRHa-untreated girls received diagnosis of PCOS more than 3 years after menarche. In the GNRHa-treated group, five girls of seven with oligomenorrhea received diagnosis of PCOS more than 3 years after menarche, while two girls had diagnosis of PCOS between 2 and 3 years after menarche. However, menstrual dysfunctions were confirmed in these two girls because they continued to present oligomenorrhea during the subsequent followup visits. Moreover, in GNRHa-treated adolescents, a significantly higher prevalence of hyperandrogenemia was detected when compared with untreated girls (56 and $23.6 \%$ respectively; $P=0.01$ ); no significant difference was detected between the two groups with regard to the prevalence of hirsutism, oligomenorrhea, and polycystic ovaries (Fig. 1).

The different PCOS phenotypes, as defined by a different combination of the diagnostic criteria, in GNRHa-treated and GNRHa-untreated girls are shown in Fig. 2.

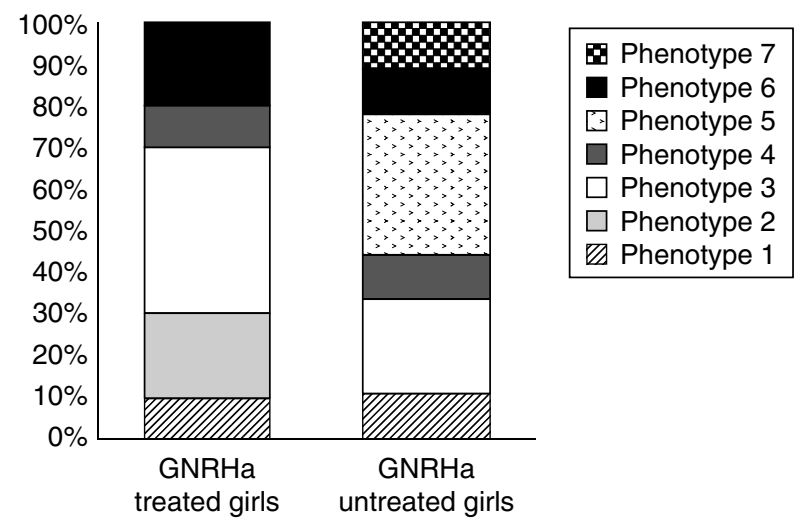

Figure 2 PCOS phenotypes in GNRHa-treated and GNRHauntreated girls at final height. Phenotype 1, menstrual dysfunctions plus polycystic ovaries; phenotype 2 , hyperandrogenemia plus polycystic ovaries; phenotype 3 , hyperandrogenemia plus hirsutism plus menstrual dysfunctions; phenotype 4, hyperandrogenemia plus hirsutism plus polycystic ovaries; phenotype 5 , hyperandrogenemia plus menstrual dysfunctions plus polycystic ovaries; phenotype 6 , hirsutism plus menstrual dysfunctions plus polycystic ovaries; phenotype 7 , hyperandrogenemia plus hirsutism plus menstrual dysfunctions plus polycystic ovaries. 
Table 2 Logistic regression: associations between PCOS, GNRHa therapy, and other main parameters.

\begin{tabular}{lcc}
\hline PCOS & $\operatorname{Exp}(\mathrm{B})(95 \%(\mathrm{Cl}))$ & $\boldsymbol{P}$ \\
\hline GNRHa therapy & $3.3(1.1-10)$ & 0.03 \\
BW & $3.1(0.7-14)$ & $\mathrm{NS}$ \\
Age at final height & $0.8(0.4-1.8)$ & $\mathrm{NS}$ \\
BMI SDS at final height & $0.8(0.4-1.4)$ & NS \\
HOMA-IR at final height & $1.1(0.7-1.6)$ & NS \\
\hline
\end{tabular}

Dependent variable PCOS: 1 , presence of PCOS; 0 , absence of PCOS. PCOS, polycystic ovary syndrome; GNRHa, GNRH analog; BW, birth weight; BMI, body mass index; HOMA-IR, homeostatic model assessment of insulin resistance.

\section{Risk of developing PCOS after GNRHa therapy}

The role of GNRHa therapy as a predictor for the development of PCOS was analyzed by single logistic regression, which documented that GNRHa treatment in girls with early puberty was significantly related to the presence of PCOS during adolescence, whereas no association was found for BW and age together with HOMA-IR and BMI SDS at final height (Table 2).

\section{Discussion}

Use of GNRHa therapy has been recognized to be effective in terms of increased final height only in girls with onset of CPP before 6 years $(3,33)$. The auxological effectiveness of gonadotropin-suppressive treatment has not been described for girls affected by early puberty. In fact, the question of final stature improvement in girls who presented this paraphysiological condition is controversial. Recently, Bouvattier et al. (1) reported that GNRHa administration for 2 years did not increase final height in a group of girls with early puberty. These findings are in agreement with our data, showing no significant result in terms of final height in a subset of girls with early puberty after GNRHa therapy. However, a significant difference was found between predicted final height and achieved final height in GNRHa-untreated girls: in fact, these girls showed a final height significantly lower than final height predicted at baseline. These results suggest that although there is no significant increment in height, GNRHa therapy seems to be helpful in reaching an adult stature close to the target height and the predicted final height. The main mechanism underlying the growth response in girls treated with GNRHa is the suppression of pituitary gonadotropin secretion, leading to BA delay with an improvement in predicted adult height (34). Lazar et al. (35) reported a significant difference in the bone maturation rate between GNRHa-treated and GNRHa-untreated girls: in fact, in the untreated girls, the higher bone maturation rate due to faster ossification of the cartilage (36) resulted in a more advanced BA at a younger chronological age, whereas in the treated girls, GNRHa slowed and arrested bone maturation for a prolonged period of time. Our results are in line with the previous findings. In fact, at the time when the treatment was stopped, we detected an attenuated bone maturation rate leading to a better predicted final height than at baseline.

Nevertheless, although our GNRHa-treated girls attained their expected predicted final height, a significant endocrine disadvantage has been found in view of the reported higher PCOS prevalence. In fact, to the best of our knowledge, this study represents the first evidence of an independent effect of GNRHa treatment in increasing the risk for PCOS during adolescence in girls with early puberty. PCOS is a heterogeneous, multigenetic syndrome characterized by a broad spectrum of clinical and biochemical features (11). Although its etiology is still unclear, neuroendocrine abnormalities such as excessive LH pulsation, dysregulation of ovarian steroidogenesis, and hyperinsulinemia seem to play a key role $(10,37)$. This syndrome represents the commonest endocrinopathy in women of reproductive years, and it has been described in $4-12 \%$ of women in the normal female population (12), in comparison to nearly $0-12 \%$ of patients with CPP after cessation of GNRHa treatment $(7,8)$. Data from the literature on the occurrence of polycystic ovaries after GNRHa therapy are discrepant. Previous studies have described an increased prevalence of polycystic ovaries and/or PCOS in girls affected by CPP after being treated with GNRHa $(18,38)$. Boepple et al. (19) detected polycystic ovaries in nearly half of the girls after GNRHa therapy, whereas a prevalence of $24 \%$ was described in another study of CCP patients who received GNRHa treatment in comparison to $2 \%$ in controls (21). In contrast, no evidence has been recently reported that GNRHa treatment predisposes to PCOS or menstrual irregularities in adulthood (39). Despite the welldescribed occurrence of PCOS in girls with a precocious pubarche and/or CPP history, the prevalence of this disorder has not been explored in girls with early puberty after GNRHa treatment. In this study, significantly higher DHEAS and androstenedione levels were detected in adolescents previously treated with GNRHa when compared with the untreated group. Furthermore, using both the AES 2006 and the Rotterdam 2003 criteria, the prevalence of PCOS was significantly higher in the treated girls than in the untreated girls, already in the early postmenarcheal years. In this respect, it needs to be acknowledged that the last visit took place at a different time length from menarche between the two groups. Theoretically, this might have a certain impact on the prevalence of PCOS, which should have been overcome by the fact that chronological age and BA were similar between GNRHa-treated and GNRHa-untreated girls. In addition, the role of GNRHa therapy as a predictor for the development of PCOS was analyzed, leading to the conclusion that GNRHa treatment in girls with early puberty was independently related to the presence of PCOS in 
adolescence. These findings suggest that GNRHa therapy seems to act as an independent risk factor for subsequent endocrine dysfunctions such as PCOS, probably because this suppressive treatment might enhance the alterations related to the complex hormonal changes associated with puberty, particularly the increased IR (13). IR and hyperinsulinemia occur physiologically during puberty due to a genetic predisposition and/or excessive adiposity, leading to high levels of free testosterone, ovarian hyperandrogenemia, and oligomenorrhea (40). In our study, insulin sensitivity was significantly decreased in adolescents previously treated with GNRHa than in the controls. However, up to now, the main cause of increased PCOS in subjects with precocious or early puberty treated with GNRHa has not been completely elucidated. Our hypothesis is that in GNRHa-treated girls, the frequent development of a pronounced weight gain could worsen these potentially adverse effects on insulin sensitivity. In fact, in our study population, a significant difference in BMI and BMI SDS was detected between the two groups at the chronological age corresponding to the end of GNRHa treatment. On the other hand, it is well known that CPP and PCOS are characterized by a disproportionate rise in LH relative to $\mathrm{FSH}$, and it has been speculated that an underlying neuroendocrine dysfunction manifests first as CPP and later as PCOS. In girls with early puberty, this abnormal gonadotropin dynamic might be enhanced by GNRHa treatment because, after an initial physiological estrogen production, this hormonal pattern is suppressed by therapy leading to estrogen depletion and to an excessive androgen exposition with clinical and/or biochemical hyperandrogenism due to adrenarche. All these changes could be responsible for adverse neuroendocrine effects of treatment, including the accumulation of body fat over lean body mass to the estrogen depletion caused by the therapy (41).

Without any doubt, the nonrandomized assignment of GNRHa treatment represents the major concern of this study. In our clinical settings, randomization was not possible as those parents who accepted therapy were those who presented particular concern on the achievement of final height. However, a possible selection bias between the two groups seems to be excluded as both groups were similar at baseline in terms of age, height, target height, BA, and androgenemia.

In summary, our data support the hypothesis that in girls with early puberty, GNRHa treatment seems to act as an independent risk factor for the development of PCOS already during adolescence. Therefore, gonadotropinsuppressive therapy does not only show no significant results in terms of gain in final height in early puberty, but it is also associated with the development of subsequent pathological conditions such as PCOS. These findings raise the question as to whether GNRHa might be administered just in few selected cases in order to avoid an increased risk of PCOS already in the early postmenarcheal years. Further studies are needed to determine the risk of developing PCOS after GNRHa therapy in girls with early puberty.

\section{Declaration of interest}

The authors declare that there is no conflict of interest that could be perceived as prejudicing the impartiality of the research reported.

\section{Funding}

This research did not receive any specific grant from any funding agency in the public, commercial, or not-for-profit sector.

\section{Acknowledgements}

We thank Dr S Fimiani and all nurses of the Department of Pediatrics and Obstetrics and Gynecology, University of Chieti, in particular D Di Santo, S Di Domenica, C Finamore, C Bene, for their daily support in clinical research and care of children.

\section{References}

1 Bouvattier C, Coste J, Rodrigue D, Teinturier C, Carel JC, Chaussain JL \& Bougnères PF. Lack of effect of GnRH agonists on final height in girls with advanced puberty: a Randomized LongTerm Pilot Study. Journal of Clinical Endocrinology and Metabolism 199984 3575-3578.

2 Orr DP \& Ingersoll GM. The contribution of level of cognitive complexity and pubertal timing to behavioral risk in young adolescents. Pediatrics 199595 528-533.

3 Carel JC, Eugster EA, Rogol A, Ghizzoni L, Palmert MR, ESPE-LWPES GnRH Analogs Consensus Conference Group, Antoniazzi F, Berenbaum S, Bourguignon JP, Chrousos GP, Coste J, Deal S, de Vries L, Foster C, Heger S, Holland J, Jahnukainen K, Juul A, Kaplowitz P, Lahlou N, Lee MM, Lee P, Merke DP, Neely EK, Oostdijk W, Phillip M, Rosenfield RL, Shulman D, Styne D, Tauber M \& Wit JM. Consensus statement on the use of gonadotropin-releasing hormone analogs in children. Pediatrics 2009123 e752-e762.

4 Kauli R, Korneich L \& Laron Z. Pubertal development, growth and final height in girls with sexual precocity after therapy with the GnRH analogue D-TRP-6-LHRH. Hormone Research 199033 $11-17$.

5 Escobar ME, Ropelato MG, Ballerini MG, Gryngarten MG, Rudaz MC, Veldhuis JD \& Barontini M. Acceleration of luteinizing hormone pulse frequency in adolescent girls with a history of central precocious puberty with versus without hyperandrogenism. Hormone Research 200768 278-285.

6 Rosenfield RL. Identifying children at risk of polycystic ovary syndrome. Journal of Clinical Endocrinology and Metabolism 2007 $92787-796$.

7 Palmert MR, Hayden DL, Mansfield MJ, Crigler JF Jr, Crowley WF Jr, Chandler DW \& Boepple PA. The longitudinal study of adrenal maturation during gonadal suppression: evidence that adrenarche is a gradual process. Journal of Clinical Endocrinology and Metabolism $2001864536-4542$.

8 Heger S, Partsch CJ \& Sippell WG. Long-term outcome after depot gonadotropin-releasing hormone agonist treatment of central precocious puberty: final height, body proportions, body composition, bone mineral density, and reproductive function. Journal of Clinical Endocrinology and Metabolism 199984 4583-4590.

9 Rosenfield RL. Does a primary acceleration of LH pulse frequency underlie an association between central precocious puberty and polycystic ovary syndrome? Commentary on Escobar ME et al.: 
acceleration of LH pulse frequency in adolescent girls with a history of central precocious puberty with versus without hyperandrogenism Hormone Research 200768 278-285.

10 Pagàn YL, Srouji SS, Jimenez Y, Emerson A, Gill S \& Hall JE. Inverse relationship between luteinizing hormone and body mass index in polycystic ovarian syndrome: investigation of hypothalamic and pituitary contributions. Journal of Clinical Endocrinology and Metabolism 200691 1309-1316.

11 Azziz R, Carmina E, Dewailly D, Diamanti-Kandarakis E, EscobarMorreale HF, Futterweit W, Janssen OE, Legro RS, Norman RJ, Taylor AE \& Witchel SF. Positions statement: criteria for defining polycystic ovary syndrome as a predominantly hyperandrogenic syndrome: an Androgen Excess Society guideline. Journal of Clinical Endocrinology and Metabolism 200691 4237-4245.

12 Knochenhauer ES, Key TJ, Kahsar-Miller M, Waggoner W, Boots LR \& Azziz R. Prevalence of polycystic ovary syndrome in unselected black and white women of the southeastern United States: a prospective study. Journal of Clinical Endocrinology and Metabolism 199883 3078-3082.

13 Franks S, McCarthy MI \& Hardy K. Development of polycystic ovary syndrome: involvement of genetic and environmental factors. International Journal of Andrology 200629 278-285.

14 Shroff R, Kerchner A, Maifeld M, Van Beek EJ, Jagasia D \& Dokras A. Young obese women with polycystic ovary syndrome have evidence of early coronary atherosclerosis. Journal of Clinical Endocrinology and Metabolism 200792 4609-4614.

15 Rossi B, Sukalich S, Droz J, Griffin A, Cook S, Blumkin A, Guzick DS \& Hoeger KM. Prevalence of metabolic syndrome and related characteristics in obese adolescents with and without polycystic ovary sindrome. Journal of Clinical Endocrinology and Metabolism 200893 4780-4786.

16 Azziz R, Marin C, Hoq L, Badamgarav E \& Song P. Health carerelated economic burden of the polycystic ovary syndrome during the reproductive life span. Journal of Clinical Endocrinology and Metabolism 200590 4650-4658.

17 Bridges NA, Cooke A, Healy JR, Hindmarsh PC \& Brook CGD. Ovaries in sexual precocity. Clinical Endocrinology 199542 135-140.

18 Jensen AM, Brocks V, Holm K, Laursen EM \& Müller J. Central precocious puberty in girls: internal genitalia before, during, and after treatment with long-acting gonadotropin-releasing hormone analogues. Journal of Pediatrics 1998132 105-108.

19 Boepple PA. Gonadotropin-releasing hormone agonist therapy of central precocious puberty: growth patterns, final heights and completion of puberty following discontinuation of treatment. In Frontiers in Paediatric Neuroendocrinology, pp 23-29. Eds MO Savage, J-P Bourguignon \& AB Grossman, Oxford, London, Edinburgh, Cambridge, Carlton: Blackwell, 1994.

20 Marshall WA \& Tanner JM. Variations in pattern of pubertal changes in girls. Archives of Disease in Childhood 196944 291-303.

21 Bridges NA, Cooke A, Healy MJ, Hindmarsh PC \& Brook CG. Standards for ovarian volume in childhood and puberty. Fertility and Sterility $1993 \mathbf{6 0} 456-460$.

22 CDC National Center for Health Statistics, Health E-Stat United States, 2003-2004 NHANES data on the Prevalence of Overweight Among Children and Adolescents.

23 Tanner JM, Goldstein H \& Whitehouse RH. Standards for children's height at ages 2-9 years allowing for heights of parents. Archives of Disease in Childhood 197045 755-762.

24 Greulich WW \& Pyle SI. Radiographic atlas of skeletal development of the hand and wrist. edn 2. Stanford, CA, USA: Stanford University Press, 1959.

25 Bayley N \& Pinneau S. Tables for predicting adult height from skeletal age: revised for use with Greulich and Pyle hand standards. Journal of Pediatrics 195214 432-441.
26 The Rotterdam ESHRE/ASRM PCOS Consensus Workshop Group. 2003 Revised consensus on diagnostic criteria and long term health risks related to polycystic ovary syndrome (PCOS). Human Reproduction 200419 41-47.

27 DeUgarte CM, Woods KS, Bartolucci AA \& Azziz R. Degree of facial and body terminal hair growth in unselected black and white women: toward a populational definition of hirsutism. Journal of Clinical Endocrinology and Metabolism 200691 1345-1350.

28 Ferriman D \& Gallwey JD. Clinical assessment of body hair growth in women. Journal of Clinical Endocrinology and Metabolism 1961 21 1440-1447.

29 Azziz R, Woods KS, Reyna R, Key TJ, Knochenhauer ES \& Yildiz BO. The prevalence and features of the polycystic ovary syndrome in an unselected population. Journal of Clinical Endocrinology and Metabolism 200489 2745-2749.

30 Chang WY, Knochenhauer ES, Bartolucci AA \& Azziz R. Phenotypic spectrum of polycystic ovary syndrome: clinical and biochemical characterization of the three major clinical subgroups. Fertility and Sterility 200583 1717-1723.

31 ESHRE/ASRM. Revised 2003 consensus on diagnostic criteria and longterm health risks related to polycystic ovary syndrome. Fertility and Sterility $2004 \mathbf{8 1} 19-25$.

32 Orsini LF, Salardi S, Pilu G, Bovicelli L \& Cacciari E. Pelvic organs in premenarcheal girls: real-time ultrasonography. Radiology $1984153113-116$.

33 Lazar L, Padoa A \& Phillip M. Growth pattern and final height after cessation of gonadotropin-suppressive therapy in girls with central sexual precocity. Journal of Clinical Endocrinology and Metabolism 200792 3483-3489.

34 Bertelloni S, Baroncelli GI, Sorrentino MC, Perri G \& Saggese G. Effect of central precocious puberty and gonadotropin-releasing hormone analogue treatment on peak bone mass and final height in females. European Journal of Pediatrics 1998157 363-367.

35 Lazar L, Kauli R, Pertzelan A \& Phillip M. Gonadotropin-suppressive therapy in girls with early and fast puberty affects the pace of puberty but not total pubertal growth or final height. Journal of Clinical Endocrinology and Metabolism 200287 2090-2094.

36 Grumbach MM \& Styne DM. Puberty: ontogeny, neuroendocrinology, physiology, and disorders. In Williams Textbook of Endocrinology, edn 9, pp 1509-1625. Eds JD Wilson \& DW Forester. Philadelphia: WB Saunders, 1998.

37 Harwood K, Vuguin P \& Di Martino-Nardi J. Current approaches to the diagnosis and treatment of polycystic ovarian syndrome in youth. Hormone Research 200768 209-217.

38 Lazar L, Kauli R, Bruchis C, Nordenberg J, Galatzer A \& Pertzelan A. Early polycystic ovary-like syndrome in girls with central precocious puberty and exaggerated adrenal response. European Journal of Endocrinology 1995133 403-406.

39 Magiakou MA, Manousaki D, Papadaki M, Hadjidakis D, Levidou G, Vakaki M, Papaefstathiou A, Lalioti N, KanakaGantenbein C, Piaditis G, Chrousos GP \& Dacou-Voutetakis C. The efficacy and safety of gonadotropin-releasing hormone analog treatment in childhood and adolescence: a single center, long-term follow-up study. Journal of Clinical Endocrinology and Metabolism 201095 109-117.

40 Barber TM, McCarthy MI, Wass JA \& Franks S. Obesity and polycystic ovary syndrome. Clinical Endocrinology 200665 137-145.

41 Boot AM, De Muinck Keizer-Schrama S, Pols HA, Krenning EP \& Drop SL. Bone mineral density and body composition before and during treatment with gonadotropin-releasing hormone agonist in children with central precocious and early puberty. Journal of Clinical Endocrinology and Metabolism 199883 370-373.

Received 25 March 2010

Accepted 26 March 2010 